\title{
REVIEW
}

\section{Survival in a bad neighborhood: pancreatic islets in cystic fibrosis}

\author{
Andrew W Norris ${ }^{1,2}$, Katie Larson Ode ${ }^{1,2}$, Lina Merjaneh³, Srinath Sanda4,5, Yaling Yi6, Xingshen Sun ${ }^{6}$, \\ John F Engelhardt2,6 and Rebecca L Hull7,8
}

\author{
1Department of Pediatrics, University of lowa, lowa City, lowa, USA \\ 2Fraternal Order of Eagles Diabetes Research Center, University of lowa, lowa City, lowa, USA \\ 3Division of Endocrinology \& Diabetes, Seattle Children's Hospital, Seattle, Washington, USA \\ ${ }_{4}^{4}$ Department of Pediatrics, University of California San Francisco, San Francisco, California, USA \\ ${ }^{5}$ Diabetes Center, University of California San Francisco, San Francisco, California, USA \\ ${ }^{6}$ Department of Anatomy and Cell Biology, University of lowa, lowa City, lowa, USA \\ 7Veterans Affairs Puget Sound Health Care System, Seattle, Washington, USA \\ ${ }^{8}$ Division of Metabolism, Endocrinology and Nutrition, Department of Medicine, University of Washington, Seattle, Washington, USA
}

Correspondence should be addressed to R L Hull: rhull@uw.edu

\begin{abstract}
In cystic fibrosis (CF), ductal plugging and acinar loss result in rapid decline of exocrine pancreatic function. This destructive process results in remodeled islets, with only a modest reduction in insulin-producing $\beta$ cells. However, $\beta$-cell function is profoundly impaired, with decreased insulin release and abnormal glucose tolerance being present even in infants with CF. Ultimately, roughly half the CF subjects develop diabetes (termed CF-related diabetes (CFRD)). Importantly, CFRD increases CF morbidity and mortality via worsening catabolism and pulmonary disease. Current accepted treatment options for CFRD are aimed at insulin replacement, thereby improving glycemia as well as preventing nutritional losses and lung decline. CFRD is a unique form of diabetes with a distinct pathophysiology that is as yet incompletely understood. Recent studies highlight emerging areas of interest. First, islet inflammation and lymphocyte infiltration are common even in young children with CF and may contribute to $\beta$-cell failure. Second, controversy exists in the literature regarding the presence/importance of $\beta$-cell intrinsic functions of CFTR and its direct role in modulating insulin release. Third, loss of the CF transmembrane conductance regulator (CFTR) from pancreatic ductal epithelium, the predominant site of its synthesis, results in paracrine effects that impair insulin release. Finally, the degree of $\beta$-cell loss in CFRD does not appear sufficient to explain the deficit in insulin release. Thus, it may be possible to enhance the function of the remaining $\beta$-cells using strategies such as targeting islet inflammation or ductal CFTR deficiency to effectively treat or even prevent CFRD.
\end{abstract}

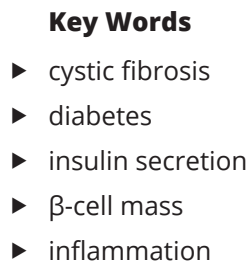

Journal of Endocrinology (2019) 241, R35-R50

\section{Overview}

Cystic fibrosis (CF) is the most common markedly life-shortening autosomal recessive genetic condition in people of Northern European descent, affecting approximately $0.05 \%$ of live births. It is caused by loss-of-function mutations in the $\mathrm{CF}$ transmembrane conductance regulator (CFTR, Table 1), resulting in the disruption of anion transport across epithelial cells predominantly in lung, gut and pancreas. This results in a 
Table 1 CFTR mutations.

\begin{tabular}{|c|c|c|c|c|c|}
\hline Mutation class & Effect on CFTR & Example & Disease & $\begin{array}{l}\text { Pancreatic insufficiency } \\
\text { risk (Ahmed et al. 2003) }\end{array}$ & Diabetes risk (Adler et al. 2008) \\
\hline I & Failed synthesis & G542X & Severe & High & High \\
\hline II & Failed protein processing & F508del & Severe & High & High \\
\hline III & Channel fails to open & G551D & Severe & High & Intermediate \\
\hline IV & Reduced channel function & R117H & Less-severe & Low & Low \\
\hline V & Reduced synthesis or processing & A455E & Less-severe & Low & Low \\
\hline
\end{tabular}

The genetics of CF are recessive, and the severity of CF disease is governed by the least severe CFTR mutation a patient carries. In most Caucasian populations, F508del is the most common mutation by far, and most CF patients have severe disease.

severe multisystem disease, with premature death usually occurring secondary to the resultant pulmonary disease. Significant improvements in the pulmonary care of patients with CF have therefore resulted in substantially greater survival.

\section{Pancreatic abnormalities in cystic fibrosis}

CFTR is essential to the function of the exocrine pancreas. Approximately $85 \%$ of CF patients develop severe exocrine pancreatic disease marked by exocrine pancreatic insufficiency (Wilschanski \& Novak 2013). In these patients, pancreatic enzyme replacement is essential to normal growth and weight gain. The risk of pancreatic insufficiency is related to CFTR mutation severity (Table 1). CFTR is highly expressed in the epithelial cells of small pancreatic ducts that drain the pancreatic acini (Marino et al. 1991) where it functions to drive secretion of chloride, water and bicarbonate into the ducts. This serves to dilute and increase the $\mathrm{pH}$ of the viscous digestive enzyme secretions from pancreatic acinar cells and thereby (i) facilitates their movement through the ductal system for delivery into the intestinal lumen and (ii) helps prevent premature activation of these proteases. When CFTR function is absent, these small ducts become dilated and plugged with the thick secretions representing the earliest pathology observed in CF pancreatic disease. Widespread acinar destruction ensues, accompanied by inflammatory cell infiltration, fatty replacement, appearance of extensive fibrosis and cystic dilation of larger ducts (Fig. 1). This can begin in utero and is extensive by 1-4 years of age such that very little acinar tissue remains (Andersen 1958). In many CF patients, the non-endocrine portion of the pancreas ultimately becomes comprised largely of adipose tissue. Importantly, the endocrine pancreas generally survives this process, albeit in a remodeled state, and with islets persisting within this highly adverse environment (Fig. 1).

\section{CF-related diabetes}

Despite the relative sparing of islets within the pancreas, a continuum of abnormalities in glucose metabolism are extremely common in subjects with $\mathrm{CF}$, encompassing impaired glucose tolerance (IGT; see Table 2 for diagnostic criteria) and CF-related diabetes (CFRD). Also, many people with $\mathrm{CF}$ have abnormally high glucose levels at intermediate time points of an oral glucose tolerance test (OGTT; i.e. 15-90 min), despite meeting conventional criteria for normal glucose tolerance (NGT; Dobson et al. 2004). Various specific criteria to define such OGTT profiles have been forwarded, termed indeterminate glycemia (INDET) or early glucose intolerance (EGI). In this review INDET/EGI, along with IGT, is collectively referred to as abnormal glucose tolerance (AGT).
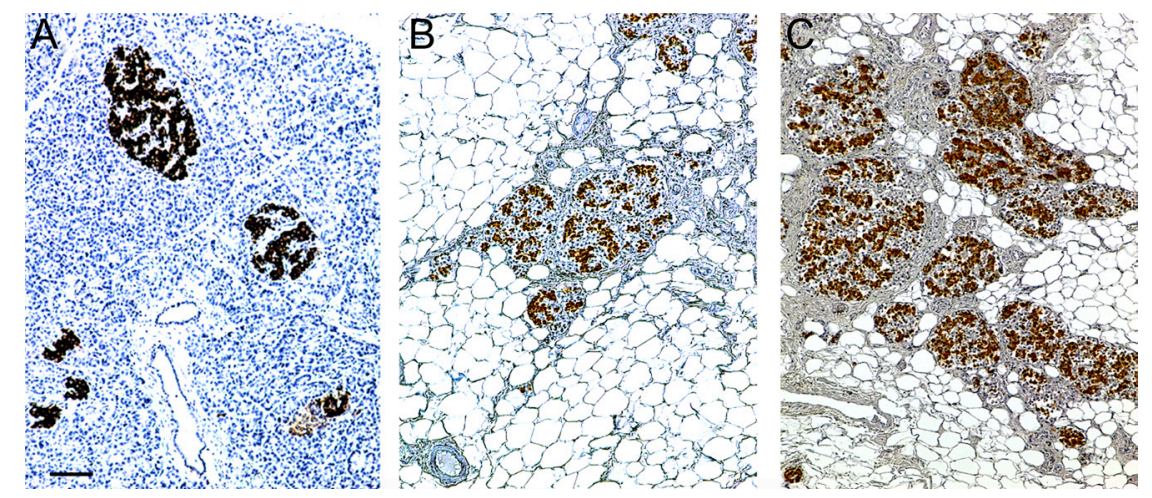

Figure 1

Pancreas morphology (hematoxylin staining) in a non-CF control ( $A ; 17$ years old), CF-no diabetes (B; 18 years) and CFRD (C; 46 years) autopsy human pancreas specimen. Extensive fatty replacement and fibrosis are evident in the CF and CFRD cases. Islets, visualized by insulin immunohistochemistry (brown), appear remodeled but clearly present in CF and CFRD even when compared to non-CF control. Scale bar $=100 \mu \mathrm{m}$ (scale bar in A applies to all panels). https://joe.bioscientifica.com https://doi.org/10.1530/JOE-18-0468 (c) 2019 Society for Endocrinology Published by Bioscientifica Ltd. Printed in Great Britain 
Table 2 Glucose tolerance categories based on OGTT.

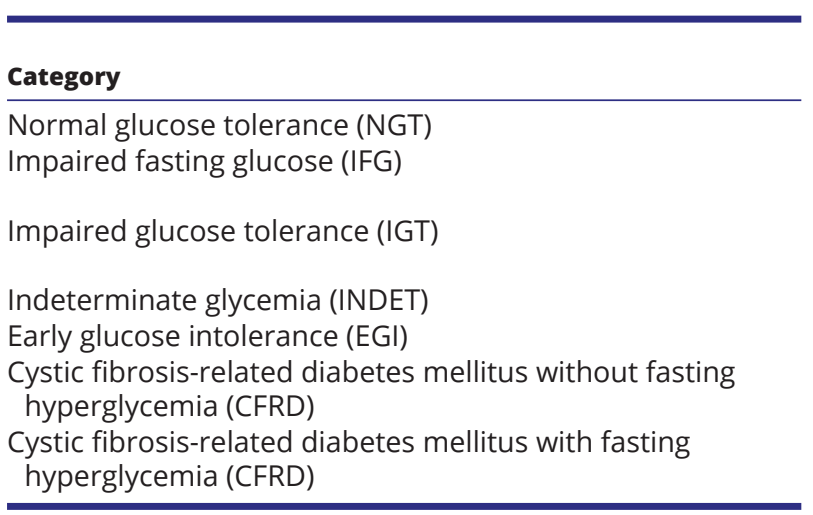

\begin{tabular}{c}
$\begin{array}{c}\text { Fasting glucose } \\
(\mathrm{mg} / \mathrm{dL}(\mathrm{mmol} / \mathrm{L}))\end{array}$ \\
\hline$<100(5.6)$ \\
$>100(5.6)$ \\
$<126(7.0)$ \\
$<126(7.0)$ \\
$<126(7.0)$ \\
$<126(7.0)$ \\
$<126(7.0)$ \\
$\geq 126(7.0)$
\end{tabular}

\begin{tabular}{l}
\hline $\begin{array}{l}\text { Intermediate time points } \\
(\mathrm{mg} / \mathrm{dL}(\mathrm{mmol} / \mathrm{L}))\end{array}$ \\
\hline$<200(11.1)$ \\
$<200(11.1)$ \\
$<200(11.1)$ \\
$>200(11.1)$ \\
$\geq 155(8.6)$ (for $1 \mathrm{~h}$ timepoint) \\
N/A \\
N/A
\end{tabular}

\begin{tabular}{l}
$\begin{array}{c}120 \text { min time point } \\
(\mathrm{mg} / \mathrm{dL}(\mathrm{mmol} / \mathrm{L}))\end{array}$ \\
\hline$<140(7.8)$ \\
$<140(7.8)$ \\
$>140(7.8)$ \\
$<200(11.1)$ \\
$<140(7.8)$ \\
$<140(7.8)$ \\
$>200(11.1)$ \\
$>200(11.1)$
\end{tabular}

N/A, not applicable.

Diabetes is one of the most common comorbidities in people with $\mathrm{CF}$, with a prevalence of $2 \%$ in children, $19 \%$ in adolescents and 40-50\% of adults (Moran et al. 2009a). Although CFRD is rare in childhood, it has been described in children of all ages including infants. Diabetes is more likely to develop in those with severe CFTR mutations (Table 1), increasing age, worse pulmonary function, under-nutrition, liver dysfunction and pancreatic insufficiency (Marshall et al. 2005). Several genetic polymorphisms outside the CFTR locus also contribute to diabetes risk among CF patients, many of which are shared with type 2 diabetes genetic risk (Blackman et al. 2013).

A significant increase in morbidity and mortality is seen in patients with CFRD compared to CF patients without diabetes, occurring secondary to worsening lung disease and respiratory failure rather than the vascular complications commonly seen in type 1 and type 2 diabetes. Age-adjusted mortality rates per 100 personyears reported in 2010 were 4.2 (3.4-5.1) in individuals with CFRD vs $1.5(1.3-1.7)$ in those with CF without diabetes (Blackman et al. 2013). CFRD-related mortality has improved significantly over time, most likely due to annual diabetes screening and early institution of insulin treatment (Moran et al. 2009a). However, of concern, mortality rates among people with CFRD who are older than 30 years have not declined in the last decade. This highlights the need for better understanding of CFRD pathophysiology and the development of improved treatments.

Compared to CF without diabetes, CFRD is associated with poorer lung function, decreased nutritional status (lower BMI), increased catabolism and higher rate of pulmonary exacerbations (Marshall et al. 2005). Even patients who have not developed CFRD but have AGT exhibit worse survival and higher lung transplant rates compared to CF patients without glucose abnormalities (Bismuth et al. 2008). People with CF with IGT at baseline have a faster rate of decline in lung function compared with those with NGT (Milla et al. 2000), and the degree of insulin deficiency is associated with a higher rate of decline. More concerning is the decline in BMI and lung function starts 4-6 years before CFRD diagnosis (Lanng et al. 1992).

Current guidelines recommend yearly OGTT screening starting at the age of 10 years (Moran et al. 2010). Diagnosis is based on the American Diabetes Association (ADA) criteria for type 1 and type 2 diabetes, even though the morbidities associated with CFRD differ from those seen in type 1 and type 2 diabetes (Moran et al. $2009 a$ ). Further, these guidelines recommend monitoring only fasting and $120 \mathrm{~min}$ OGTT glucose levels; yet, CF patients with elevated 60-min OGTT glucose levels are at high risk for worsening pulmonary disease (Brodsky et al. 2011). Additionally, continuous glucose monitoring has shown that even CF patients with NGT commonly have intermittent, asymptomatic hyperglycemia (Moreau et al. 2008). Together, these data suggest that current diagnostic criteria fail to capture all CF patients at risk for clinical decline due to impairments in glucose metabolism.

\section{Abnormal glucose tolerance is an early-life feature of cystic fibrosis}

As outlined earlier, in cystic fibrosis (CF), even mild hyperglycemia is associated with significant decline in lung function (Milla et al. 2000). However, even though CF lung disease begins in the first years of life, glucose levels in very young children had not been characterized until very recently. This decade, data from CF animal models demonstrated glucose abnormalities starting at birth 
(Olivier et al. 2012, Uc et al. 2015, Yi et al. 2016b). Additionally, data from humans showed that AGT in 6- to 10-year-old children with CF predicts early progression to CFRD (Ode et al. 2010). Although there are no systematic outcome studies of the long-term implications of earlylife glycemic abnormalities in humans with CF, anecdotal evidence comes from a case report which describes an infant with hyperglycemia at 3 months, who developed waxing and waning glucose intolerance through childhood, finally culminating in CFRD with insulin requirement at 13 years (Fattorusso et al. 2017), much earlier than the usual onset of CFRD, which has a median age of onset typically in the third decade of life.

Exocrine pancreatic disease in CF begins prior to birth, and is progressive thereafter, with $23 \%$ of children $<1$ year of age having severe exocrine pancreatic loss, compared to $75 \%$ of 1-4 year olds (Andersen 1958, Bogdani et al. 2017). This early exocrine pancreatic pathology may have an important bearing on later CFRD risk. In fact, a greater degree of exocrine pancreatic disease at birth, as reflected by lower circulating immunoreactive trypsinogen levels, predicts increased risk for CFRD in later life (Soave et al. 2014). Early life exocrine pancreatic disease may also drive endocrine pancreas pathology, as young children with CF already exhibit loss of islet $\beta$ cells and islet inflammation (Bogdani et al. 2017, Hull et al. 2018). Such early pathological changes in the endocrine pancreas may be functionally important, since cross-sectional data from a cohort of children aged 3 months to 5 years showed the greatest frequency of AGT at 2-4 years of age followed by a lower AGT frequency at 5-6 years (Yi et al. 2016a). Together, these findings support an overarching relationship between exocrine pancreatic pathology, islet pathology/dysfunction and AGT in CF.

\section{Impaired insulin secretion is a key determinant of hyperglycemia in cystic fibrosis}

In $\mathrm{CF}$ subjects, $\beta$-cell function is substantially reduced compared to non-CF controls - even in patients with NGT (Merjaneh et al. 2015, Sheikh et al. 2017). This is clearly demonstrated in CF patients by measuring the disposition index (DI). DI is a robust measure of $\beta$-cell function quantified as the insulin response during an oral GTT, normalized for the prevailing insulin sensitivity, and is a strong predictor of future type 1 and type 2 diabetes in non-CF populations. DI is low in the general CF population, demonstrating an insulin secretory defect that exists even during stable pulmonary disease and adequate nutritional status (Merjaneh et al. 2015, Sheikh et al. 2017). First-phase insulin secretion is particularly impaired and represents an early abnormality in the development of AGT among those with CF (Mohan et al. 2009, Sheikh et al. 2017). Furthermore, relative proinsulin secretion is elevated in CF patients who have AGT (Sheikh et al. 2017, Nyirjesy et al. 2018), providing additional evidence for early $\beta$-cell dysfunction. These studies confirm that, in CF, $\beta$-cell dysfunction is present before deterioration of glucose tolerance is apparent and long before the diagnosis of diabetes.

While impaired insulin secretion worsens with age, likely in all pancreatic insufficient CF subjects regardless of glycemic status (Moran et al. 2009a, Ode et al. 2010, Yi et al. 2016a), abnormal insulin secretion is already detectable in young people with CF and is potentially present from birth. Evidence for the latter comes in part from CF animal models which develop spontaneous hyperglycemia; these exhibit abnormal insulin responses from birth (Olivier et al. 2012, Uc et al. 2015). Furthermore, very young humans with CF (3 months to 5 years of age) fail to exhibit the normal increase in insulin secretion seen in non-CF subjects within the same age range (Yi et al. 2016a). In addition, young CF subjects with AGT show an inability to increase insulin secretion even in the face of hyperglycemia (Yi et al. 2016a). Six- to ten-year-old CF children also have a delayed insulin response, which is more pronounced in those with AGT (Ode et al. 2010).

Overall, the literature suggests that even CF subjects with NGT have low $\beta$-cell reserve, which places them at risk for the development of hyperglycemia. Further, the clinical implications of a low $\beta$-cell reserve are likely more important in CF than in non-CF subjects given their catabolic state and the detrimental effects of insulin deficiency on weight gain and lung function in CF patients.

\section{Islet pathology in cystic fibrosis}

As mentioned earlier, exocrine pancreas pathology is a major feature of $\mathrm{CF}$, occurring due to pancreatic ductal plugging and extensive involution of acini (Andersen 1958). In line with this, pancreatic volume, estimated by MRI, is decreased in CF compared to healthy controls and to patients with type 1 diabetes (note, however, pancreas could only be visualized in a small subset of CF subjects; Sequeiros et al. 2010). While destruction of the exocrine pancreatic acini is near total in CF, many ducts survive, 
especially larger ones, and islets are still present within the fibrotic/fatty pancreas parenchyma (Fig. 1).

In subjects with CF without a diabetes diagnosis, compared to non-CF controls, most studies report a decrease in $\beta$-cell area (Abdul-Karim et al. 1986, Lohr et al. 1989, Couce et al. 1996, Hart et al. 2018) ranging from 11 to $52 \%$. $\beta$-cell loss appears to be particularly severe in younger subjects (Bogdani et al. 2017), but does not differ between subjects that exhibit fatty vs fibrotic exocrine pancreas pathology (Lohr et al. 1989). The manner in which $\beta$-cell measures are expressed affects interpretation of the data $\beta$-cell area, when expressed relative to islet area, is reduced in most studies (Abdul-Karim et al. 1986, Lohr et al. 1989, Couce et al. 1996, Bogdani et al. 2017). $\beta$-cell normalized to pancreatic area was found to be decreased in one study (Hart et al. 2018), but unchanged in others (Bogdani et al. 2017, Hull et al. 2018). Such differences may be due to difficulties in distinguishing pancreas-intrinsic fat (i.e. that which is present due to fatty replacement) from fat which is located close to the pancreas.

In CF subjects with diabetes, studies demonstrating $\beta$-cell loss (relative to islet area) are relatively small $(n \leq 8$ in at least one group) but consistent, reporting a decrease of $\sim 25-30 \%$ (Iannucci et al. 1984, Soejima \& Landing 1986, Bogdani et al. 2017). Interestingly, two larger studies ( $n=12-18$ subjects per group) failed to find significant loss in $\beta$-cell area when quantified per islet area (Couce et al. 1996, Hull et al. 2018) or per pancreas area (Hull et al. 2018). Taken together, the literature is somewhat mixed but shows that loss of $\beta$ cells may be a feature of CF both with and without diabetes.

An increase in glucagon-positive $\alpha$-cells has been described in CF subjects both with and without diabetes (Lohr et al. 1989, Bogdani et al. 2017, Hart et al. 2018, Hull et al. 2018), with only one study reporting no difference (Abdul-Karim et al. 1986). Similarly, the fraction of somatostatin-positive $\delta$-cells is increased in humans with CF (Abdul-Karim et al. 1986, Soejima \& Landing 1986, Lohr et al. 1989, Bogdani et al. 2017), with two other studies showing the same trend (Hart et al. 2018, Hull et al. 2018). PP cell area has also been shown to be increased in subjects with CF vs non-CF controls (Lohr et al. 1989, Hull et al. 2018). A significant decrease in PP cells between CF subjects with and without diabetes was reported in one study (Hull et al. 2018) with no difference being observed in another (Iannucci et al. 1984). The relative areas of ghrelin-positive $\epsilon$ cells do not appear to have been determined in CF pancreas.

Abnormalities in non-endocrine islet components, particularly nerve fibers and/or islet capillaries, may also contribute to the islet lesion in CF. This has not been well studied, although data from a pig model of CF suggest that pancreatic/islet vascularization appears normal while nerve fiber density (determined by PGP9.5 immunoreactivity) may be reduced (Uc et al. 2015).

In summary, it is clear that the extent of $\beta$-cell loss seen in (human) CF is not as severe as the loss of pancreatic acini, nor as the loss of $\beta$-cell mass seen in type 1 diabetes. Even if $50 \%$ or more of $\beta$-cell mass was lost in CFRD, a functional $\beta$-cell defect must also exist to explain the magnitude of observed insulin secretion impairment. This raises the possibility that the function of remaining $\beta$-cells could be targeted for therapy to improve insulin release in CF. From the literature, it is clear that non- $\beta$ islet endocrine cells (i.e. $\alpha, \delta$ and PP cells) are increased in CF/CFRD. This alteration in islet composition suggests that paracrine interactions among islet endocrine cells are likely to be disturbed, which could contribute to $\beta$-cell dysfunction and impaired glucose metabolism in CF subjects.

\section{Release of other islet hormones is also abnormal in cystic fibrosis}

Inappropriately elevated glucagon levels are postulated to contribute to hyperglycemia and hepatic insulin resistance in type 2 diabetes, while an inappropriately low counter-regulatory glucagon response is an important contributor to hypoglycemia in diabetes. An insufficient glucagon response to arginine has been reported in CF subjects with impaired insulin release (Uc et al. 2015). Additionally, glucagon responses to hypoglycemia are impaired in CF subjects with pancreatic insufficiency, but are intact in exocrine sufficient CF subjects (Moran et al. 1991). Glucagon suppression during glucose loading has been found to be both impaired (i.e. poor suppression, especially in subjects with AGT; Lanng et al. 1993b), and normal, albeit decreasing from a reduced baseline level (Sheikh et al. 2017). Despite these inconsistencies, the literature supports that dysregulated glucagon release may be a feature of CF.

Somatostatin is secreted by islet $\delta$ cells and potently inhibits insulin and glucagon secretion through paracrine action. In CFRD patients compared to normal controls, plasma somatostatin is increased following arginine stimulation (Meacham et al. 1993), though it is not known if this reflects somatostatin secreted from islets or other locations with somatostatin secreting cells (such as the gut). Nonetheless, these data suggest that somatostatin 
tone is increased in CF and that increased somatostatin may therefore contribute to poor insulin secretion in CF.

Pancreatic polypeptide (PP) is released by PP cells of the islet in response to feeding. Circulating PP levels fail to increase in response to feeding in CF patients across a range of ages (Allen et al. 1983). The PP response to hypoglycemia is also decreased, more so in patients with exocrine insufficiency (Moran et al. 1991). PP release during an OGTT is likewise severely impaired (Lanng et al. $1993 b)$.

While the data suggest that levels of non- $\beta$-cell islet hormones are differentially altered in CF (i.e. glucagon and PP levels are largely decreased, while somatostatin levels may be increased), the morphological data show that $\alpha, \delta$ and PP cell areas are all increased. Thus, there exists a disconnect between the frequency of these non$\beta$-endocrine cells and release of their hormone contents, further supporting the concept that functional, rather than morphological abnormalities represent the key pathogenic defect in the islet in CF.

\section{Animal models of CFRD}

Until recently, experimental study of CFRD has been hampered due to a lack of suitable animal models. Mouse models of cystic fibrosis, including Cftr-knockout and Cftr- $\Delta$ F508 mice, exhibit severe gastrointestinal disease and impaired growth but do not develop substantive pancreatic or lung disease. Blood glucose in CF mice is normal (Lanng et al. 1993b) or even reduced (Fontes et al. 2015) during glucose tolerance testing. Mice with acute- or chronic $\beta$-cell-specific Cftr deletion demonstrate normal glucose tolerance and do not exhibit altered insulin release in response to glucose or IBMX (Hart et al. 2018). Likewise, Cftr KO rats have a normal pancreas, although their glycemic phenotype is yet to be detailed. By contrast, cftr-knockout zebrafish undergo exocrine pancreatic destruction, though their glycemic phenotype also has yet to be described. CFTR-knockout pigs and ferrets develop lung disease and severe gastrointestinal disease, requiring specialized care similar to humans with CF. Importantly, they also develop exocrine pancreatic disease which phenocopies human pancreatic CF including ductal plugging, acinar destruction, ductal dilation, inflammation, fibrosis, fatty replacement and relative sparing of endocrine mass (Sun et al. 2014, Uc et al. 2015, Yi et al. 2016b). Both models develop hyperglycemia with impaired insulin secretion (Uc et al. 2015, Yi et al. $2016 b$ ). As in humans, these abnormalities are detected in early life. Newborn CFTR-knockout (KO) pigs have abnormal glucose tolerance, extensive exocrine pancreatic disease and impaired insulin secretion (Uc et al. 2015). Similarly, newborn CFTR KO ferret kits have decreased firstphase insulin secretion and abnormal glucose tolerance, but only mild exocrine pancreatic disease consisting of ductal plugging, pancreatic stellate cell activation, with no inflammatory infiltrate or cell apoptosis/necrosis (Olivier et al. 2012). Interestingly, CF ferrets experience an earlylife hyperglycemic phase (Yi et al. 2016b), similar to that observed in humans with CF (Yi et al. 2016a), and which correlate with histopathologic changes in the pancreas (Yi et al. 2016b). In the first several weeks after birth, exocrine pancreatic disease accelerates in CF ferrets, culminating at 4-8 weeks in severe pancreas inflammation, inflammatory cell infiltration, extensive loss of insulin positivity within islets and spontaneous diabetes. Strikingly, insulin positivity and islet hormone mRNA expression reappear thereafter and blood glucose levels spontaneously normalize. This occurs as loss of acinar tissue becomes complete, inflammation recedes, and a fibrotic to adipogenic transition initiates fatty replacement of the exocrine pancreas. The islets are remodeled, with altered shape, size and cellular composition (Rotti et al. 2018). This euglycemic reprieve is temporary and is followed by a persistent decline in glucose tolerance, with this final phase being very similar to the clinical picture of CFRD in teenage and adult humans with CF (Yi et al. 2016a). Unfortunately, widespread utility of the CF pig and ferret models has been limited by the required technical expertise to rear these fragile animals and the related expense. Two approaches, currently being undertaken, will hopefully mitigate technical and expense barriers, allowing widespread study of clinically relevant CFRD models. Firstly, recent gene-editing advances should enable re-engineering of the ferret and/or pig CF models to ameliorate their fragile state. Secondly, creation of murine model(s) of spontaneous CFRD, for example, through humanization of pancreatic biology as has been done in other forms of diabetes, could also greatly propel CFRD research.

\section{Potential mechanisms underlying loss of $\beta$-cell function in CF}

\section{Islet inflammation}

Several studies have investigated the possibility that islet-intrinsic mechanisms may underlie the decline in $\beta$-cell function that characterizes CF. The concept that 
pro-inflammatory cytokines can elicit $\beta$-cell cytotoxicity is well established in the literature. However, whether $\beta$-cell dysfunction result from localized islet inflammation is somewhat controversial, with the production of cytokines, especially IL-1 $\beta$, from $\beta$-cells themselves being a particularly contentious issue. Surprisingly, immunoreactivity for IL- $1 \beta$, which appears to localize to endocrine cells, is a robust and common feature of CF islet pathology (Hull et al. 2018). Two other studies recently described immune infiltration in islets from CF human autopsy pancreas sections, including in children younger than 4 years of age (Bogdani et al. 2017, Hart et al. 2018). This leukocyte infiltration is chiefly composed of T-cells (CD8+ and CD4+), but not macrophages (Bogdani et al. 2017, Hart et al. 2018, Hull et al. 2018). It is clear that the islet pathology in CF differs from the profound autoimmune-mediated $\beta$-cell destruction seen in type 1 diabetes. However, these new data demonstrating the presence of T-lymphocytes in CF islets warrants additional study, as localized inflammation and presence of T-cells in the islet appear to be common features of CF. These findings, together with data from other forms of diabetes and from CF animal models, indicate that $\beta$-cells and/or other cells in the islet are likely to also express other proinflammatory cytokines (aside from IL-1 $\beta$ ) and chemokines, further contributing to islet inflammation. It is possible that this islet inflammation, especially if it occurs acutely, is a survival mechanism activating recovery and repair mechanisms. However, chronic inflammation is likely to be detrimental to $\beta$-cell function and survival, and may therefore represent a therapeutic target for CFRD.

\section{Islet amyloid deposition}

Islet amyloid formation is a long-recognized pathological hallmark of type 2 diabetes, which is toxic to $\beta$-cells and is associated with decreased insulin release in animal models (Hull et al. 2004). Islet amyloid deposition has been documented in CF (Iannucci et al. 1984, Couce et al. 1996, Hart et al. 2018, Hull et al. 2018), most commonly in CFRD ( $70 \%$ of subjects), with $17 \%$ of those with CF and 'borderline diabetes' also being affected (Couce et al. 1996). Islet amyloid is rarer in adult CF subjects without diabetes and has not been observed in children with CF (Bogdani et al. 2017, Hull et al. 2018). It is striking, though, that the age at which amyloid is frequently seen in CFRD (on average around 28 years) is decades earlier than that typically described in type 2 diabetes (Hull et al. 2004), suggesting that this cytotoxic process may be accelerated in CF. Interestingly, despite well-documented proinflammatory effects of islet amyloid (Masters et al. 2010, Westwell-Roper et al. 2011), IL-1 $\beta$ immunoreactivity in CF is not always coincident with islet amyloid deposition. In fact, the presence of IL- $1 \beta$ reactivity is much more widespread than amyloid, being present in adults with and without diabetes, and in children (Hull et al. 2018).

\section{Islet endocrine cell autonomous actions of CFTR}

There has been considerable interest in the possibility that CFTR might have direct actions in $\beta$-cells and/or other islet endocrine cells. This interest stems in part from CFTR's primary function as a chloride channel. It has long been postulated that chloride channels should contribute to $\beta$-cell electrophysiology (Di Fulvio et al. 2014), and there are several molecules that could fulfill or contribute to this function. CFTR would be one such candidate; it is closely related phylogenetically to the sulfonylurea receptor, both are members of the ABCC subfamily of $\mathrm{ABC}$ (ATP-binding cassette) transport proteins and the latter is known to be critical for $\beta$-cell function. Some studies provide data in support of CFTR activity in the $\beta$ cell; evidence for this has been previously reviewed in detail (Koivula et al. 2016). However, conflicting data also exist and as such this issue remains highly controversial.

In 2007, Cftr mRNA and CFTR protein expression was first reported in primary rat islet $\beta$ cells and RIN-5mF insulinoma cells, at levels lower than those in 'non- $\beta$ cells' (Boom et al. 2007). Subsequent studies confirmed that RIN-5mF and MIN6 cells both express detectable CFTR (Guo et al. 2014, Ntimbane et al. 2016). Isolated primary human $\beta$ cells were reported to have immunoreactivity for CFTR, although mRNA data were not reported (Guo et al. 2014). Newer data from the same group (Edlund et al. 2017) show the presence of scattered CFTR immunoreactive cells in a representative human islet, but the proportion of CFTR-positive cells, which are also insulin positive was not determined. In contrast, other groups did not detect CFTR in $\beta$ cells, by immunohistochemistry (Boom et al. 2007, Hart et al. 2018) or in situ hybridization (Sun et al. 2017), from rat, ferret and human pancreas, or based on data from the Human Protein Atlas (Uhlen et al. 2015, Hart et al. 2018). Further, analysis of data from two single-cell RNASeq transcript datasets, representing over 12,000 single cells dispersed from isolated human islets (Baron et al. 2016, Segerstolpe et al. 2016) demonstrated an average CFTR expression per $\beta$ cell of $0.14 \pm 0.47$ reads per kilobase million (RPKM) or $1.05 \pm 1.02$ transcripts per million (TPM), respectively. In these two studies, 
pancreatic $\beta$ - and ductal cells comprised $12-29 \%$ and $13-17 \%$ of islet cell types, respectively. By comparison, these same analyses demonstrated an average CFTR expression per ductal cell of $308 \pm 250$ RPMK or $207 \pm 827$ TPM, respectively. Additional analyses using one of these same datasets (Segerstolpe et al. 2016) along with bulk RNA-Seq datasets from mouse and human $\beta$ cells (Bramswig et al. 2013, Blodgett et al. 2015) also found CFTR mRNA is detectable only at low levels ( $<6 \mathrm{RPKM})$, in a small proportion ( $\sim 5 \%)$ of $\beta$ cells (Hart et al. 2018). In sum, the available data suggest that if CFTR is produced in the $\beta$ cell, its expression is low and/or occurs only in a minority of cells.

The extent to which $\beta$ cells express CFTR, or not, is of critical importance because CFTR is expected to exert effects on $\beta$ cell electrical activity and thus impact insulin secretion. The presence of CFTR in a minority of $\beta$ cells could still have functional consequences if those cells were highly electrically active (such as 'hub' $\beta$ cells; Johnston et al. 2016); however, the presence of CFTR in such cells has not been demonstrated. CFTR-knockdown and/or pharmacological inhibition of CFTR activity in immortalized $\beta$-cell lines results in reduced glucosestimulated membrane depolarization (Guo et al. 2014) and reduced glucose-stimulated insulin secretion (Ntimbane et al. 2016). The presence of an cAMP (forskolin)-induced chloride whole cell current has been documented in isolated mouse and human $\beta$-cells; this can be partially blocked with small-molecule CFTR inhibitors and is absent in $\beta$-cells from mice with global expression of the $\Delta$ F508 Cftr mutation (Edlund et al. 2014, Guo et al. 2014, Ntimbane et al. 2016). Furthermore, murine $\beta$ cells from $\Delta$ F508 mice or with pharmacological inactivation of CFTR exhibited membrane hyperpolarization and slower glucose-stimulated membrane depolarization, reduced generation of action potentials and smaller rises in intracellular calcium levels (Guo et al. 2014). Isolated human and mouse $\beta$ cells treated with small-molecule CFTR inhibitors exhibited no alteration of voltage-dependent calcium currents but showed blocked depolarizationevoked membrane capacitance (a measure of secretory granule exocytosis) (Edlund et al. 2014). In contrast to both these studies, recent data from human $\beta$ cells failed to detect any forskolin-activated chloride current (Hart et al. 2018), although the patch clamp conditions utilized differed from the previous publications, precluding direct comparisons of the data.

Some important caveats regarding specificity are important to bear in mind when interpreting the above studies. The two CFTR inhibitors used in the above studies, CFTR(inh)-172 and GlyH-101, are not specific for CFTR activity at the concentrations employed, $10 \mu \mathrm{M}$ (Guo et al. 2014), and 10-40 and $40-50 \mu \mathrm{M}$ respectively (Edlund et al. 2014). Both compounds inhibit mitochondrial function at $10 \mu \mathrm{M}$ (Kelly et al. 2010) and the activity of other chloride channels at $5 \mu \mathrm{M}$ (Kelly et al. 2010, Melis et al. 2014, Friard et al. 2017 and reviewed in Di Fulvio et al. 2014). Furthermore, $20 \mu \mathrm{M}$ CFTR(inh)-172 has been shown to reduce glucose-stimulated calcium currents and insulin secretion in CFTR-KO ferret islets (GlyH-101 not tested) (Sun et al. 2017), indicating that this compound, at the concentration used, likely has islet actions which are independent of CFTR. Secondly, sufficient data exist in the literature to warrant caution in the interpretation of CFTR immunoreactivity. Specifically, a variety of CFTR antibodies exhibit aberrant labeling, including non-specific labeling of cells which do not express CFTR (van Meegen et al. 2013, Hart et al. 2018) and varying sensitivity for detection of low CFTR quantities (relevant for its detection in islet endocrine cells). Taken together, studies using inhibitors and antibodies directed against CFTR should be interpreted with these caveats in mind.

Data regarding insulin release in conditions of pharmacological or genetic inactivation of CFTR are also conflicting. Use of small-molecule CFTR inhibitors or islets from mice bearing the $\Delta \mathrm{F} 508 \mathrm{Cftr}$ mutation resulted in reduced glucose-stimuated insulin release (GSIS) in one study (Guo et al. 2014). In contrast, data from mouse and human islets using the same CFTR inhibitors showed no effect on glucose-stimulated insulin release but reported inhibition of forskolin-augmented insulin release (Edlund et al. 2014). Similar to both studies, studies of ferret islets showed both glucose-stimulated insulin secretion and forskolin-amplified insulin secretion were impaired in perifused islets isolated from CFTR-KO vs control ferrets (Sun et al. 2017). Additionally, a CFTR inhibitor reduced insulin secretion from islets isolated from normal ferret and human islets, but also reduced insulin secretion in islets from CFTR-KO ferrets indicating non-specific inhibitor effects (Sun et al. 2017). Further contrasting data from mouse islets with acute or chronic $\beta$-cell selective CFTR deletion show no differences in glucose- or IBMXmediated insulin release (Hart et al. 2018). This same study also showed no effect of CFTR activators to modulate insulin release in response to glucose or forskolin in human islets (Hart et al. 2018), and, importantly, also found no difference in insulin release from perifused islets derived from human donors with or without CF (Hart et al. 2018). 
There has also been considerable interest in whether CFTR may influence $\alpha$-cell function. CFTR immunoreactivity has been reported in human, rat and mouse $\alpha$-cells (Boom et al. 2007, Edlund et al. 2017). This is in contrast to studies showing no CFTR immunoreactivity in $\alpha$-cells from human islets and no CFTR RNA in $\alpha$-cells of ferret pancreas or in dispersed islet cells from ferrets and humans (Sun et al. 2017, Hart et al. 2018). As an aside, all four of these studies agree that CFTR immunoreactivity is absent from islet $\delta$ cells (Boom et al. 2007, Edlund et al. 2017, Sun et al. 2017, Hart et al. 2018). A CFTR inhibitor enhanced glucagon secretion from human and mouse islets in response to low glucose + forskolin (Edlund et al. 2017). The effect of this inhibitor was abrogated in human islets by siRNA-mediated CFTR knockdown, although CFTR knockdown did not itself influence glucagon release.

In summary, there has been great interest in whether there may be islet $\beta$ - and $\alpha$-cell autonomous actions for CFTR. Conflicting data exist regarding whether endogenous CFTR expression and electrical activity occur in these cells and could thereby influence insulin secretion. Even if these effects do exist, pancreatic ductal cells remain the major site of CFTR expression in the pancreas, raising the possibility that CFTR expression in these cells may explain some or all of the effects of CFTR on insulin secretion (as detailed in the next section).

\section{Potential paracrine actions of CFTR on $\beta$-cell function}

In the pancreas, CFTR is expressed predominantly, if not almost exclusively, in the ductal epithelium (Marino et al. 1991, Wilschanski \& Novak 2013 and Fig. 2). CFTR expression is highest in those duct cells nearest acini, especially centroacinar and intercalated duct cells (Marino et al. 1991, Wilschanski \& Novak 2013). Islets share a physically close association with pancreatic ducts, and it is postulated that ductal cells influence islet function via paracrine mechanisms (Bertelli \& Bendayan 2005). Based on the essential requirement of CFTR for proper ductal function (Wilschanski \& Novak 2013) and because ducts are the major site of CFTR expression in the pancreas, it has been postulated that loss of CFTR from ductal epithelium contributes to islet dysfunction in CF via paracrine mechanisms.

The concept that islet function can be regulated by paracrine factors (along with multiple other inputs: autocrine, endocrine, neural, etc.) is established in the literature, providing support for such a hypothesis. In fact, persistence of pancreatic ductal-derived cells in preparations of isolated islets, even following several days of culture or after transplantation, has been well documented in the literature (Warnock et al. 2005, Keymeulen et al. 2006, Ichii et al. 2008, Segerstolpe et al. 2016, Sun et al. 2017 and Fig. 3). Further, cultured islet preparations from humans and ferrets contain ductal cells which express CFTR at much higher levels than endocrine cells (as illustrated in Fig. 2 and; Baron et al. 2016, Segerstolpe et al. 2016, Sun et al. 2017, Hart et al. 2018).

Given these data, it is possible that the persistence of CFTR-expressing ductal cells in isolated islet preparation could exert effects on insulin release and explain/ confound some of the existing studies in the literature. Indeed, we utilized this property of isolated islets to test the hypothesis that CFTR expressed in ductal cells may influence insulin secretion. Acute knockdown of CFTR in human and ferret islets does indeed result in decreased glucose-stimulated insulin secretion in static islet cultures (Fig. 4; see Supplementary Methods, see section on supplementary data given at the end of this article). Since ductal cells were the only cell type in these studies to express CFTR mRNA (Sun et al. 2017), these results suggest that CFTR-dependent paracrine actions from isletassociated ductal cells are crucial for insulin secretion and provides an additional or alternative mechanism to the role of intrinsic CFTR action in $\beta$ - (or $\alpha$ )-cells. The mechanism underlying this effect remains to be determined, and whether this effect occurs in vivo is also currently unknown. If this observation does translate to the in vivo situation, it suggests that restoration of ductal CFTR action may be an effective strategy to improve insulin secretion and therefore treat CFRD.

\section{Influence of extra-pancreatic factors on islets in CF}

Gastrointestinal disease is prominent in CF and levels of several gut hormones that impact islet function have been shown to be deranged in CF patients. Active glucagon-like peptide-1 (GLP1) responses during mixed meal testing vary between studies, being normal or low (Hillman et al. 2012, Sheikh et al. 2017). By contrast, gastric inhibitory polypeptide (GIP) levels during mixed meal testing are more consistently decreased in $\mathrm{CF}$ patients, especially those who are pancreatic insufficient (Sheikh et al. 2017). Fasting plasma acyl-ghrelin levels in CF patients are elevated (Cohen et al. 2008), but the potential connection of ghrelin to CFRD has not been explored. Although low GLP-1 and GIP and elevated ghrelin would be expected to potentially contribute to diminished $\beta$-cell function, evidence suggest there 


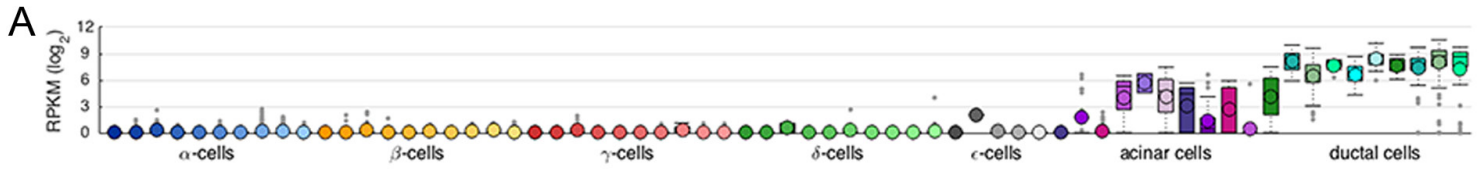

B

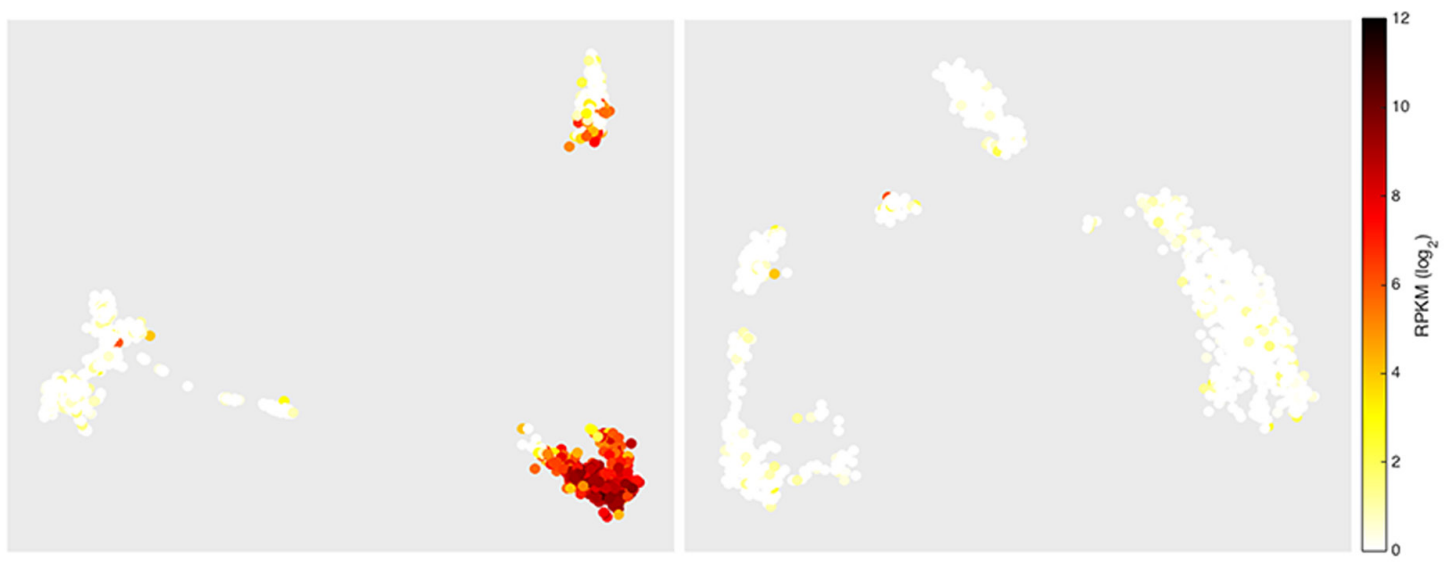

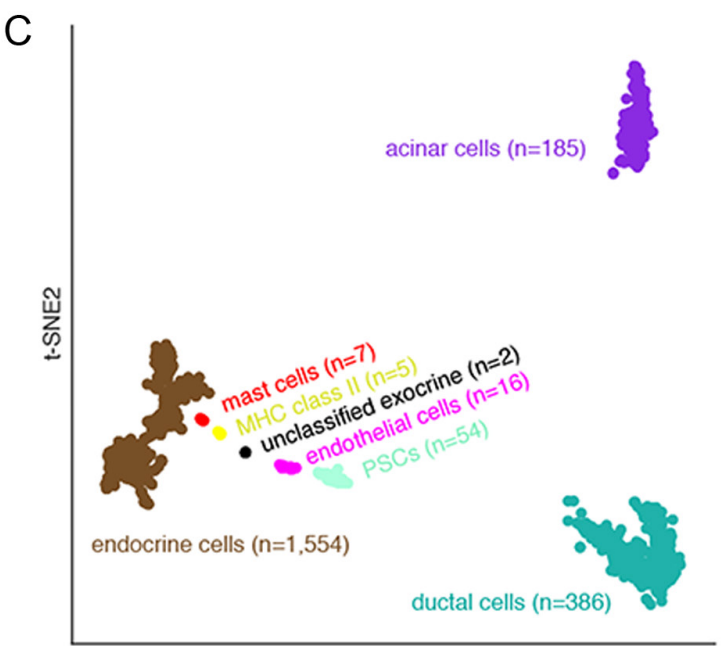

t-SNE1

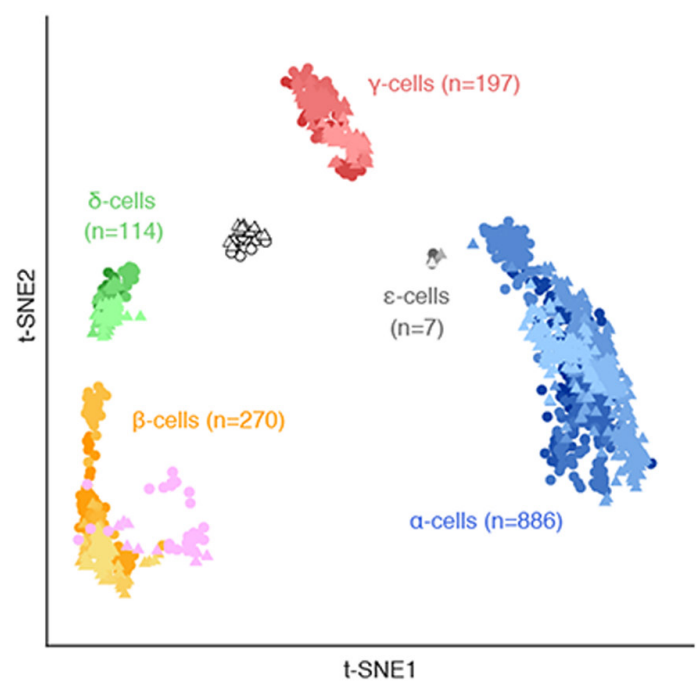

Figure 2

CFTR expression in isolated cells from human islet preparations. Data captured from (Segerstolpe et al. 2016 as visualized at http://sandberg.cmb.ki.se/ pancreas/). (A) Single cell RNAseq results for CFTR expression in isolated islets collected from 10 individuals. Boxplots summarize CFTR expression in Reads Per Kilobase of transcript per Million reads (RPKM) on a log2 scale across the 7 major cell types for each donor. The first 6 boxes for each cell-type correspond to healthy individuals and the last 4 to individuals with type 2 diabetes. (B) t-SNE plot of cells grouped by transcriptome similarity and colored according to CFTR expression according to the indicated log2 RPKM scale. (C) Legend indicating cell types. (B and C) Left panels show all cell types $(n=2209)$ and right panels show endocrine cell types only $(n=1554)$.

is no epidemiological linkage of relative GLP-1 and GIP deficiency to declining glucose tolerance in CF (Lanng et al. 1993a, Nyirjesy et al. 2018). A very recent small study evaluating a GLP-1 receptor agonist did show improved glucose excursion in CF patients with impaired glucose tolerance; however, this appeared to be primarily secondary to slowing of gastric emptying, indicating that abnormalities in incretin function, have a complex relationship to the pathophysiology of CFRD (Geyer et al. 2019). Relatedly, available literature supports the hypothesis that meticulous attention to pancreatic enzyme supplementation decreases postprandial hyperglycemia in $\mathrm{CF}$, by improving incretin secretion and by slowing gastric emptying (Perano et al. 2014).

\section{Insulin resistance and cystic fibrosis}

Although insulin resistance is not a prominent clinical feature of patients with CF at baseline health, studies employing sensitive techniques have repeatedly demonstrated insulin resistance in CF patients 

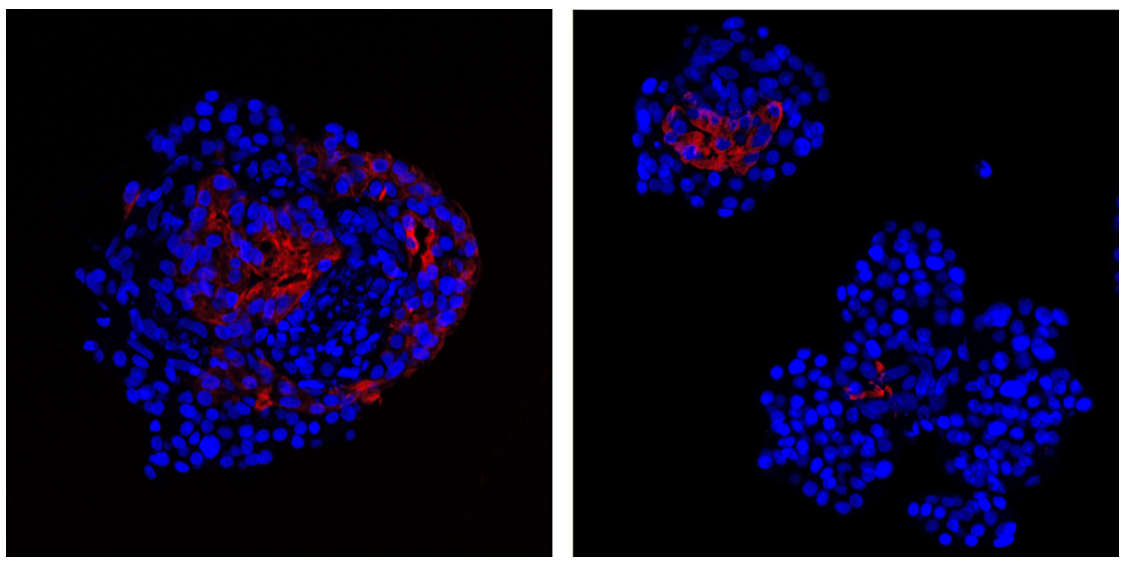

Figure 3

Presence of cytokeratin 7-positive duct cells (red) in isolated human islets, immediately upon receipt from the IIDP. Cytokeratin 7 immunoreactivity was detected using the anti-Cytokeratin 7 antibody EPR1619Y from AbCam (catalogue no. ab68459) based on the approach described in Sun et al. (2017).

(as reviewed in; Yi et al. 2016b). Exocrine pancreatic status predicts insulin sensitivity in CF patients. Those CF patients who are exocrine pancreatic sufficient exhibit comparable insulin sensitivity to non-CF subjects. However, CF patients with exocrine pancreatic insufficiency demonstrate primarily hepatic insulin resistance, the mechanistic origins of which are not well understood. Additionally, transient insulin resistance is common in CF patients owing to systemic inflammation during pulmonary infections and also due to systemic corticosteroid treatment when used. It is therefore likely that insulin resistance in CF increases stress on the $\beta$-cells and thus contributes to their dysfunction.

\section{Specific considerations for the treatment of diabetes in cystic fibrosis}

Unique to CFRD, compared to other forms of diabetes mellitus, the primary goal of treatment is preservation of lung function. Weight and BMI maintenance is also essential to survival in CF, as CFRD induces a catabolic
A

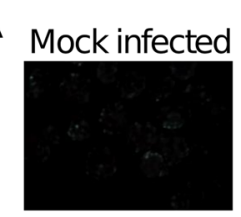

Ad.fCFTR-shRNA

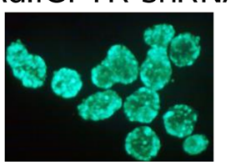

B

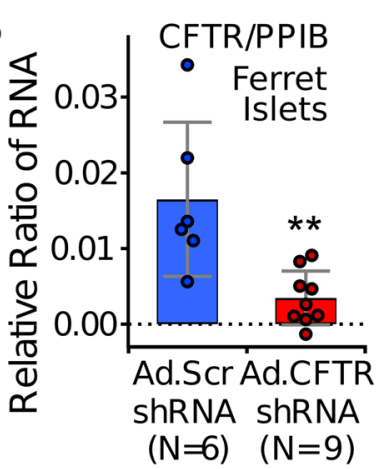

C Ad.Scr-shRNA

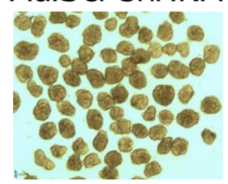

Ad.fCFTR-shRNA

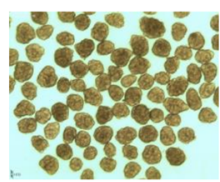

D

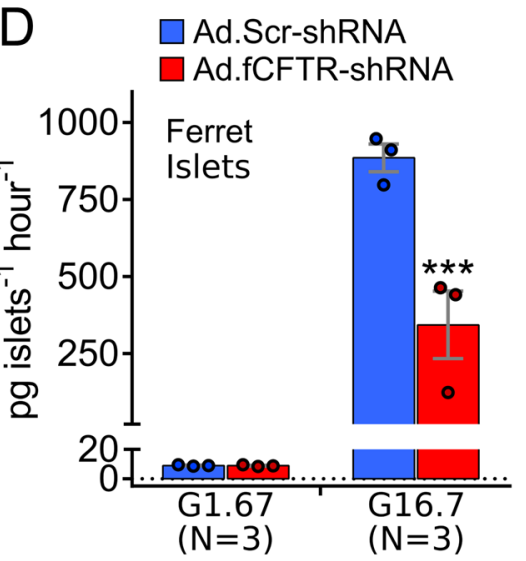

E

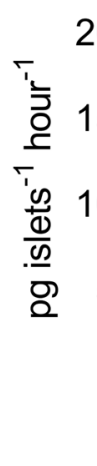

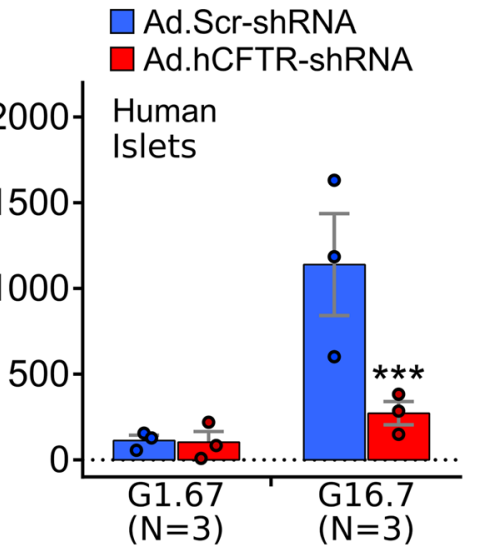

\section{Figure 4}

CFTR-knockdown in wild-type adult ferret and human islets reduces glucose stimulated insulin secretion. (A) Infection of adult ferret islets with a fCFTR-shRNA expressing recombinant adenovirus (Ad.fCFTR-ShRNA) that contains a CMV-driven EGFP transgene in the $\mathrm{E} 3$ region of the virus. Fluorescent photomicrographs of mock and Ad.fCFTR-shRNA infected islets are shown. (B) Evaluation of $f C F T R$ and housekeeping (PPIB) RNA levels in CF and WT adult ferret islets $48 \mathrm{~h}$ following Ad.fCFTR-shRNA or Ad.Scr-shRNA (scrambled control) infection. Plots represent mean \pm S.E.M. for $N$ experiments; $* * P<0.01$, two-tailed student's t-test. (C) Photomicrograph of adult ferret islets $48 \mathrm{~h}$ following infection with Ad.fCFTR-shRNA and Ad.Scr-shRNA. (D and E) Insulin secretion in response to $1.67 \mathrm{mmol} / \mathrm{L}$ glucose (G1.67) or $16.7 \mathrm{mmol} / \mathrm{L}$ glucose (G16.7) by adult WT ferret islets (D) and human islets (E) $48 \mathrm{~h}$ following infection with Ad.fCFTR-shRNA, Ad.hCFTR-shRNA, or Ad.Scr-shRNA as indicated. (D and E) Graphs show the mean \pm S.E.M. for the $N$ independent batches, with dots showing the mean per batch performed on 1-4 replicates. Statistical analysis comparing Scr-shRNA vs CFTR-shRNA within each glucose category was performed by mixed effects modeling treating batch replicates as repeated measures using the R package nlme; $* * * P \leq 0.0001$. 
state that contributes to clinical decline in CF patients. Insulin is the only currently recommended medical treatment for CFRD (Moran et al. 2010), as it is the only agent to date that has been shown to prevent BMI decline in CFRD patients (Moran et al. 2009b). The advent of aggressive insulin treatment for CFRD has narrowed the survival gap between CF patients with and without CFRD. However, insulin treatment is labor intensive for patients and so it would significantly improve quality of life if other less complex treatments were effective for CFRD. Unfortunately, there is a paucity of adequate data to support the use of other treatments at this time. Several smaller clinical studies have examined the efficacy of various oral type 2 diabetes medications to treat CFRD, though none have yielded sufficient evidence to produce consensus recommending their use (Moran et al. 2010). Although sulfonylurea and meglinide secretagogues stimulate insulin secretion in CF patients, two clinical trials using repaglinide have failed to produce durable improvements in BMI among CFRD patients (Moran et al. 2009b, Ballmann et al. 2018). Comprehensive review of the clinical literature on the remaining pharmaceutical classes currently used to treat type 2 diabetes is beyond this scope of this article. However, several conceptual considerations are informative. Many of these agents (which include biguanides, alpha-glucosidase inhibitors, incretin mimetics, DPP-4 inhibitors, amylin and glycosurics) promote some degree of catabolism through weight loss, appetite reduction, macronutrient malabsorption and/or glucose wasting. Thus, use or investigation of any of these agents for CFRD treatment must cautiously track and assess their effect on catabolism and body mass. Although thiazolidinediones have been shown to increase weight in type 2 diabetes, their side effect of reducing bone mineral density could be very problematic for CF patients, who are at markedly increased risk for osteoporosis at baseline.

There has been considerable recent progress in understanding the pathophysiology of CFRD, potentially unveiling new possible treatment or preventative approaches. Given the prominent role of exocrine pancreatic inflammation, which is especially extreme in the young pancreas but persists even after resolution of the inflammatory infiltrate, it is tempting to wonder whether anti-inflammatory agents might treat CFRD. Focusing on the endocrine pancreas, there is precedent which comes from the connection of islet inflammation, amyloidosis and type 2 diabetes (Masters et al. 2010,
Westwell-Roper et al. 2011, Marchetti 2016). Clinical trials using anti-inflammatories in type 2 diabetes have met with mixed results. Anakinra, an IL-1 receptor antagonist, demonstrated improvements in insulin secretion, fasting glucose and glycated hemoglobin in a phase 2 study of 70 adults (Larsen et al. 2007). However, in a larger study using canakinumab, a monoclonal antibody against IL-1 $\beta$, non-sustained reductions in hemoglobin A1c were observed in 10,061 patients, suggesting limitations to anti-inflammatory therapy in type 2 diabetes (Everett et al. 2018). Despite these results, the presence of islet inflammation/infiltration and the degree of islet amyloidosis in relatively young CF patients could indicate that responses to anti-inflammatory medications may be more effective than in other forms of diabetes (Couce et al. 1996, Bogdani et al. 2017, Hart et al. 2018, Hull et al. 2018). Of course, given that CF patients are extremely susceptible to fatal lung infection, agents that dampen the immune system must be approached with extreme caution unless delivered selectively to the pancreas.

The over-abundance of $\delta$ cells in the CF islet suggests that there may be increased paracrine inhibition of insulin release by somatostatin. In such a case, it is conceivable that a selective somatostatin receptor antagonist might improve $\beta$-cell function. Indeed such agents have been considered for treatment of type 2 diabetes. Smallmolecule inhibition of the glucagon receptor has also been tested in the context of type 2 diabetes. Despite favorable effects on lowering glucose levels, concerns of hepatic transaminitis may limit this approach in patients with cystic fibrosis. GLP-1-based therapies have several desirable properties that might be beneficial in CFRD, including augmentation of insulin secretion and inhibition of glucagon release. The potential efficacy of GLP-1-based therapy in cystic fibrosis subjects is currently under study.

Recent advances in gene editing technologies have reignited interest and enthusiasm for gene and cell-based therapies of CF affected organs. While the current focus has primarily been on the lung, whether correction of CFTR mutations by gene editing in the CF pancreas would reverse the course of disease is an interesting prospect. The question as to which pancreatic cell type(s) are responsible for CFTR actions that ultimately support insulin secretion is paramount to determining which therapeutic strategy should be employed and underscores the critical nature of future work to resolve the marked discrepancies in the current literature. https://joe.bioscientifica.com

https://doi.org/10.1530/JOE-18-0468
(C) 2019 Society for Endocrinology Published by Bioscientifica Ltd.
Printed in Great Britain 


\section{Looking forward}

Remarkable progress has been made in pulmonary care for patients with $\mathrm{CF}$, leading to significant improvements in longevity. However, there have been no concomitant advances that reduce the burden of diabetes among CF patients. A new era of CF care is dawning, as small-molecule drugs that restore CFTR function and dramatically improve lung function have recently come into clinical use. It remains to be determined how these agents will impact long-term diabetes risk. Because of the CF pancreatic defects incurred early in life, the utility of CFTR restoring drugs for treating CFRD is not yet clear. Early-life treatment may be required in order to prevent pancreatic pathology. On the other hand, these drugs might help treat or prevent CFRD by recovering CFTR-dependent islet-associated ductal function, by improving gut incretin function, and/or by reducing the inflammation and insulin resistance of systemic illness. Given these uncertainties, it is crucial to understand all of the pathophysiologic drivers of CFRD, so that we can design preventative strategies to ameliorate the morbidity and mortality of this disease.

Recent advances in both animal models and translational human studies have shed light on the pathogenesis of CFRD but more work on the fundamental mechanisms of disease is needed. Future work should focus on understanding the precise role of islet inflammation in CFRD, including the role, if any, of amyloid deposition, better understanding the cellular and molecular details underlying impaired insulin secretion, and defining the mechanisms underlying CFTR dependent pancreatic duct/endocrine cross-talk. Because $\beta$-cell mass is relatively well retained in CFRD, with greater knowledge it may be possible to enhance the function of the remaining $\beta$-cells and thus effectively prevent and treat CFRD.

\section{Supplementary data}

This is linked to the online version of the paper at https://doi.org/10.1530/ JOE-18-0468.

\section{Declaration of interest}

Rebecca Hull is a Senior Editor of the Journal of Endocrinology. Rebecca Hull was not involved in the review or editorial process for this paper, on which she is listed as an author. The other authors have nothing to disclose.

\section{Funding}

This work was supported by National Institute of Diabetes and Digestive and Kidney Diseases awards R01DK115791, R24DK096518 and P30DK089507, UK Cystic Fibrosis Trust (SRC007), Cystic Fibrosis Foundation awards R565CR11, SINGH15R0, VERKMA15R0, MERJAN17AB and HULL16I0 and a faculty scholar award from the Fraternal Order of Eagles Diabetes Research Center.

\section{Author contribution statement}

$\mathrm{R} \mathrm{L} \mathrm{H}$ and A W N conceived the outline for this review. All authors reviewed and discussed the relevant literature, were responsible for drafting the article and reviewing it critically for important intellectual content. X S, Y Y, J F E and A W N conceived and designed the studies shown in Fig. 4; these were conducted by $X S$ and $Y Y$. Editing was performed by $A W N, K L O$, J F E and R L H. All authors approved the version to be published.

\section{Acknowledgements}

Many excellent articles are unfortunately not cited here due to limitations on the number of references allowed, but these were considered and discussed during the writing of this article. The authors apologize to those whose work is not directly acknowledged.

\section{References}

Abdul-Karim FW, Dahms BB, Velasco ME \& Rodman HM 1986 Islets of Langerhans in adolescents and adults with cystic fibrosis. A quantitative study. Archives of Pathology and Laboratory Medicine 110 602-606.

Adler AI, Shine BS, Chamnan P, Haworth CS \& Bilton D 2008 Genetic determinants and epidemiology of cystic fibrosis-related diabetes: results from a British cohort of children and adults. Diabetes Care $\mathbf{3 1}$ 1789-1794. (https://doi.org/10.2337/dc08-0466)

Ahmed N, Corey M, Forstner G, Zielenski J, Tsui LC, Ellis L, Tullis E \& Durie P 2003 Molecular consequences of cystic fibrosis transmembrane regulator (CFTR) gene mutations in the exocrine pancreas. Gut 52 1159-1164. (https://doi.org/10.1136/gut.52.8.1159)

Allen JM, Penketh AR, Adrian TE, Lee YC, Sarson DL, Hodson ME, Batten JC \& Bloom SR 1983 Adult cystic fibrosis: postprandial response of gut regulatory peptides. Gastroenterology 85 1379-1383.

Andersen DH 1958 Cystic fibrosis of the pancreas. Journal of Chronic Diseases 7 58-90. (https://doi.org/10.1016/0021-9681(58)90185-1)

Ballmann M, Hubert D, Assael BM, Staab D, Hebestreit A, Naehrlich L, Nickolay T, Prinz N, Holl RW, Staden U, et al. 2018 Repaglinide versus insulin for newly diagnosed diabetes in patients with cystic fibrosis: a multicentre, open-label, randomised trial. Lancet Diabetes and Endocrinology 6 114-121. (https://doi.org/10.1016/S22138587(17)30400-X)

Baron M, Veres A, Wolock SL, Faust AL, Gaujoux R, Vetere A, Ryu JH, Wagner BK, Shen-Orr SS, Klein AM, et al. 2016 A single-cell transcriptomic map of the human and mouse pancreas reveals interand intra-cell population structure. Cell Systems 3 346.e344-360.e344. (https://doi.org/10.1016/j.cels.2016.08.011)

Bertelli E \& Bendayan M 2005 Association between endocrine pancreas and ductal system. More than an epiphenomenon of endocrine differentiation and development? Journal of Histochemistry and Cytochemistry 53 1071-1086. (https://doi.org/10.1369/ jhc.5R6640.2005)

Bismuth E, Laborde K, Taupin P, Velho G, Ribault V, Jennane F, Grasset E, Sermet I, de BJ, Lenoir G, et al. 2008 Glucose tolerance and insulin secretion, morbidity, and death in patients with cystic fibrosis. Jurnalul Pediatrului 152 540-545. (https://doi.org/10.1016/j. jpeds.2007.09.025)

Blackman SM, Commander CW, Watson C, Arcara KM, Strug LJ, Stonebraker JR, Wright FA, Rommens JM, Sun L, Pace RG, et al. 2013 Genetic modifiers of cystic fibrosis-related diabetes. Diabetes $\mathbf{6 2}$ 3627-3635. (https://doi.org/10.2337/db13-0510) https://joe.bioscientifica.com

https://doi.org/10.1530/JOE-18-0468 (c) 2019 Society for Endocrinology Published by Bioscientifica Ltd. Printed in Great Britain 
Blodgett DM, Nowosielska A, Afik S, Pechhold S, Cura AJ, Kennedy NJ, Kim S, Kucukural A, Davis RJ, Kent SC, et al. 2015 Novel observations from next-generation RNA sequencing of highly purified human adult and fetal islet cell subsets. Diabetes 64 3172-3181. (https://doi. org/10.2337/db15-0039)

Bogdani M, Blackman SM, Ridaura C, Bellocq JP, Powers AC \& AguilarBryan L 2017 Structural abnormalities in islets from very young children with cystic fibrosis may contribute to cystic fibrosis-related diabetes. Scientific Reports 7 17231. (https://doi.org/10.1038/s41598017-17404-z)

Boom A, Lybaert P, Pollet JF, Jacobs P, Jijakli H, Golstein PE, Sener A, Malaisse WJ \& Beauwens R 2007 Expression and localization of cystic fibrosis transmembrane conductance regulator in the rat endocrine pancreas. Endocrine 32 197-205. (https://doi.org/10.1007/s12020-0079026-x)

Bramswig NC, Everett LJ, Schug J, Dorrell C, Liu C, Luo Y, Streeter PR, Naji A, Grompe M \& Kaestner KH 2013 Epigenomic plasticity enables human pancreatic alpha to beta cell reprogramming. Journal of Clinical Investigation 123 1275-1284. (https://doi.org/10.1172/ JCI66514)

Brodsky J, Dougherty S, Makani R, Rubenstein RC \& Kelly A 2011 Elevation of 1-hour plasma glucose during oral glucose tolerance testing is associated with worse pulmonary function in cystic fibrosis. Diabetes Care 34 292-295. (https://doi.org/10.2337/dc10-1604)

Cohen RI, Tsang D, Koenig S, Wilson D, McCloskey T \& Chandra S 2008 Plasma ghrelin and leptin in adult cystic fibrosis patients. Journal of Cystic Fibrosis 7 398-402. (https://doi.org/10.1016/j.jcf.2008.02.002)

Couce M, O'Brien TD, Moran A, Roche PC \& Butler PC 1996 Diabetes mellitus in cystic fibrosis is characterized by islet amyloidosis. Journal of Clinical Endocrinology and Metabolism 81 1267-1272. (https://doi. org/10.1210/jcem.81.3.8772610)

Di Fulvio M, Brown PD \& Aguilar-Bryan L 2014 Chloride channels and transporters in $\beta$-cell physiology. In The Islets of Langerhans. Ed. MS Islam. New York, NY, USA: Springer-Verlag, pp. 401-451.

Dobson L, Sheldon CD \& Hattersley AT 2004 Conventional measures underestimate glycaemia in cystic fibrosis patients. Diabetic Medicine 21 691-696. (https://doi.org/10.1111/j.1464-5491.2004.01219.x)

Edlund A, Esguerra JL, Wendt A, Flodstrom-Tullberg M \& Eliasson L 2014 CFTR and anoctamin 1 (ANO1) contribute to cAMP amplified exocytosis and insulin secretion in human and murine pancreatic beta-cells. BMC Medicine 12 87. (https://doi.org/10.1186/1741-701512-87)

Edlund A, Pedersen MG, Lindqvist A, Wierup N, Flodstrom-Tullberg M \& Eliasson L 2017 CFTR is involved in the regulation of glucagon secretion in human and rodent alpha cells. Scientific Reports 790. (https://doi.org/10.1038/s41598-017-00098-8)

Everett BM, Donath MY, Pradhan AD, Thuren T, Pais P, Nicolau JC, Glynn RJ, Libby P \& Ridker PM 2018 Anti-inflammatory therapy with canakinumab for the prevention and management of diabetes. Journal of the American College of Cardiology $\mathbf{7 1}$ 2392-2401. (https://doi. org/10.1016/j.jacc.2018.03.002)

Fattorusso V, Casale A, Raia V, Mozzillo E \& Franzese A 2017 Long-term follow-up in a girl with cystic fibrosis and diabetes since the first year of life. Diabetes Therapy 8 1187-1190. (https://doi.org/10.1007/ s13300-017-0289-9)

Fontes G, Ghislain J, Benterki I, Zarrouki B, Trudel D, Berthiaume Y \& Poitout V 2015 The deltaF508 mutation in the cystic fibrosis transmembrane conductance regulator is associated with progressive insulin resistance and decreased functional beta-cell mass in mice. Diabetes 64 4112-4122. (https://doi.org/10.2337/db14-0810)

Friard J, Tauc M, Cougnon M, Compan V, Duranton C \& Rubera I 2017 Comparative effects of chloride channel inhibitors on LRRC8/VRACmediated chloride conductance. Frontiers in Pharmacology 8328. (https://doi.org/10.3389/fphar.2017.00328)

Geyer MC, Sullivan T, Tai A, Morton JM, Edwards S, Martin AJ, Perano SJ, Gagliardi L, Rayner CK, Horowitz M, et al. 2019 Exenatide corrects postprandial hyperglycaemia in young people with cystic fibrosis and impaired glucose tolerance: a randomized crossover trial. Diabetes, Obesity and Metabolism 21 700-704. (https://doi.org/10.1111/ dom.13544)

Guo JH, Chen H, Ruan YC, Zhang XL, Zhang XH, Fok KL, Tsang LL, Yu MK, Huang WQ, Sun X, et al. 2014 Glucose-induced electrical activities and insulin secretion in pancreatic islet beta-cells are modulated by CFTR. Nature Communications 5 4420. (https://doi. org/10.1038/ncomms5420)

Hart NJ, Aramandla R, Poffenberger G, Fayolle C, Thames AH, Bautista A, Spigelman AF, Babon JAB, DeNicola ME, Dadi PK, et al. 2018 Cystic fibrosis-related diabetes is caused by islet loss and inflammation. JCI Insight 3. (https://doi.org/10.1172/jci.insight.98240)

Hillman M, Eriksson L, Mared L, Helgesson K \& Landin-Olsson M 2012 Reduced levels of active GLP-1 in patients with cystic fibrosis with and without diabetes mellitus. Journal of Cystic Fibrosis 11 144-149. (https://doi.org/10.1016/j.jcf.2011.11.001)

Hull RL, Westermark GT, Westermark P \& Kahn SE 2004 Islet amyloid: a critical entity in the pathogenesis of type 2 diabetes. Journal of Clinical Endocrinology and Metabolism 89 3629-3643. (https://doi.org/10.1210/ jc.2004-0405)

Hull RL, Gibson RL, McNamara S, Deutsch GH, Fligner CL, Frevert CW, Ramsey BW \& Sanda S 2018 Islet interleukin-1beta immunoreactivity is an early feature of cystic fibrosis that may contribute to beta-cell failure. Diabetes Care 41 823-830. (https://doi.org/10.2337/dc17-1387)

Iannucci A, Mukai K, Johnson D \& Burke B 1984 Endocrine pancreas in cystic fibrosis: an immunohistochemical study. Human Pathology $\mathbf{1 5}$ 278-284. (https://doi.org/10.1016/S0046-8177(84)80191-4)

Ichii H, Miki A, Yamamoto T, Molano RD, Barker S, Mita A, RodriguezDiaz R, Klein D, Pastori R, Alejandro R, et al. 2008 Characterization of pancreatic ductal cells in human islet preparations. Laboratory Investigation 88 1167-1177. (https://doi.org/10.1038/ labinvest.2008.87)

Johnston NR, Mitchell RK, Haythorne E, Pessoa MP, Semplici F, Ferrer J, Piemonti L, Marchetti P, Bugliani M, Bosco D, et al. 2016 Beta cell hubs dictate pancreatic islet responses to glucose. Cell Metabolism 24 389-401. (https://doi.org/10.1016/j.cmet.2016.06.020)

Kelly M, Trudel S, Brouillard F, Bouillaud F, Colas J, Nguyen-Khoa T, Ollero M, Edelman A \& Fritsch J 2010 Cystic fibrosis transmembrane regulator inhibitors CFTR(inh)-172 and Gly H-101 target mitochondrial functions, independently of chloride channel inhibition. Journal of Pharmacology and Experimental Therapeutics 333 60-69. (https://doi.org/10.1124/jpet.109.162032)

Keymeulen B, Gillard P, Mathieu C, Movahedi B, Maleux G, Delvaux G, Ysebaert D, Roep B, Vandemeulebroucke E, Marichal M, et al. 2006 Correlation between beta cell mass and glycemic control in type 1 diabetic recipients of islet cell graft. PNAS 103 17444-17449. (https:// doi.org/10.1073/pnas.0608141103)

Koivula FNM, McClenaghan NH, Harper AGS \& Kelly C 2016 Isletintrinsic effects of CFTR mutation. Diabetologia 59 1350-1355. (https://doi.org/10.1007/s00125-016-3936-1)

Lanng S, Thorsteinsson B, Nerup J \& Koch C 1992 Influence of the development of diabetes mellitus on clinical status in patients with cystic fibrosis. European Journal of Pediatrics 151 684-687. (https://doi. org/10.1007/BF01957574)

Lanng S, Thorsteinsson B, Pociot F, Marshall MO, Madsen HO, Schwartz M, Nerup J \& Koch C 1993a Diabetes mellitus in cystic fibrosis: genetic and immunological markers. Acta Paediatrica 82 150-154. (https://doi.org/10.1111/j.1651-2227.1993.tb12628.x)

Lanng S, Thorsteinsson B, Roder ME, Orskov C, Holst JJ, Nerup J \& Koch C 1993b Pancreas and gut hormone responses to oral glucose and intravenous glucagon in cystic fibrosis patients with normal, impaired, and diabetic glucose tolerance. Acta Endocrinologica 128 207-214. (https://doi.org/10.1530/acta.0.1280207)

Larsen CM, Faulenbach M, Vaag A, Volund A, Ehses JA, Seifert B, Mandrup-Poulsen T \& Donath MY 2007 Interleukin-1-receptor https://joe.bioscientifica.com

https://doi.org/10.1530/JOE-18-0468 (c) 2019 Society for Endocrinology Published by Bioscientifica Ltd. Printed in Great Britain 
antagonist in type 2 diabetes mellitus. New England Journal of Medicine 356 1517-1526. (https://doi.org/10.1056/NEJMoa065213)

Lohr M, Goertchen P, Nizze H, Gould NS, Gould VE, Oberholzer M, Heitz PU \& Kloppel G 1989 Cystic fibrosis associated islet changes may provide a basis for diabetes. Virchows Archiv A: Pathological Anatomy and Histopathology 414 179-185. (https://doi.org/10.1007/ BF00718598)

Marchetti P 2016 Islet inflammation in type 2 diabetes. Diabetologia 59 668-672. (https://doi.org/10.1007/s00125-016-3875-x)

Marino CR, Matovcik LM, Gorelick FS \& Cohn JA 1991 Localization of the cystic fibrosis transmembrane conductance regulator in pancreas. Journal of Clinical Investigation 88 712-716. (https://doi.org/10.1172/ JCI115358)

Marshall BC, Butler SM, Stoddard M, Moran AM, Liou TG \& Morgan WJ 2005 Epidemiology of cystic fibrosis-related diabetes. Journal of Pediatrics 146 681-687. (https://doi.org/10.1016/j.jpeds.2004.12.039)

Masters SL, Dunne A, Subramanian SL, Hull RL, Tannahill GM, Sharp FA, Becker C, Franchi L, Yoshihara E, Chen Z, et al. 2010 Activation of the NLRP3 inflammasome by islet amyloid polypeptide provides a mechanism for enhanced IL-1beta in type 2 diabetes. Nature Immunology 11 897-904. (https://doi.org/10.1038/ni.1935)

Meacham LR, Caplan DB, McKean LP, Buchanan CN, Parks JS \& Culler FL 1993 Preservation of somatostatin secretion in cystic fibrosis patients with diabetes. Archives of Disease in Childhood 68 123-125. (https:// doi.org/10.1136/adc.68.1.123)

Melis N, Tauc M, Cougnon M, Bendahhou S, Giuliano S, Rubera I \& Duranton C 2014 Revisiting CFTR inhibition: a comparative study of CFTRinh -172 and Gly H inhibitors. British Journal of Pharmacology 171 3716-3727. (https://doi.org/10.1111/bph.12726)

Merjaneh L, He Q, Long Q, Phillips LS \& Stecenko AA 2015 Disposition index identifies defective beta-cell function in cystic fibrosis subjects with normal glucose tolerance. Journal of Cystic Fibrosis 14 135-141. (https://doi.org/10.1016/j.jcf.2014.06.004)

Milla CE, Warwick WJ \& Moran A 2000 Trends in pulmonary function in patients with cystic fibrosis correlate with the degree of glucose intolerance at baseline. American Journal of Respiratory and Critical Care Medicine 162 891-895. (https://doi.org/10.1164/ ajrccm.162.3.9904075)

Mohan K, Miller H, Dyce P, Grainger R, Hughes R, Vora J, Ledson M \& Walshaw M 2009 Mechanisms of glucose intolerance in cystic fibrosis. Diabetic Medicine 26 582-588. (https://doi.org/10.1111/j.14645491.2009.02738.x)

Moran A, Diem P, Klein DJ, Levitt MD \& Robertson RP 1991 Pancreatic endocrine function in cystic fibrosis. Journal of Pediatrics 118 715-723. (https://doi.org/10.1016/S0022-3476(05)80032-0)

Moran A, Dunitz J, Nathan B, Saeed A, Holme B \& Thomas W 2009a Cystic fibrosis-related diabetes: current trends in prevalence, incidence, and mortality. Diabetes Care 32 1626-1631. (https://doi. org/10.2337/dc09-0586)

Moran A, Pekow P, Grover P, Zorn M, Slovis B, Pilewski J, Tullis E, Liou TG, Allen H \& Cystic Fibrosis Related Diabetes Therapy Study $2009 b$ Insulin therapy to improve BMI in cystic fibrosis-related diabetes without fasting hyperglycemia: results of the cystic fibrosis related diabetes therapy trial. Diabetes Care 32 1783-1788. (https:// doi.org/10.2337/dc09-0585)

Moran A, Brunzell C, Cohen RC, Katz M, Marshall BC, Onady G, Robinson KA, Sabadosa KA, Stecenko A \& Slovis B 2010 Clinical care guidelines for cystic fibrosis-related diabetes: a position statement of the American Diabetes Association and a clinical practice guideline of the Cystic Fibrosis Foundation, endorsed by the Pediatric Endocrine Society. Diabetes Care 33 2697-2708. (https://doi.org/10.2337/dc10-1768)

Moreau F, Weiller MA, Rosner V, Weiss L, Hasselmann M, Pinget M, Kessler R \& Kessler L 2008 Continuous glucose monitoring in cystic fibrosis patients according to the glucose tolerance. Hormone and Metabolic Research 40 502-506. (https://doi. org/10.1055/s-2008-1062723)
Ntimbane T, Mailhot G, Spahis S, Rabasa-Lhoret R, Kleme ML, Melloul D, Brochiero E, Berthiaume Y \& Levy E 2016 CFTR silencing in pancreatic beta-cells reveals a functional impact on glucosestimulated insulin secretion and oxidative stress response. American Journal of Physiology: Endocrinology and Metabolism 310 E200-E212. (https://doi.org/10.1152/ajpendo.00333.2015)

Nyirjesy SC, Sheikh S, Hadjiliadis D, De Leon DD, Peleckis AJ, Eiel JN, Kubrak C, Stefanovski D, Rubenstein RC, Rickels MR, et al. 2018 Beta-cell secretory defects are present in pancreatic insufficient cystic fibrosis with 1-hour oral glucose tolerance test glucose $\geq 155 \mathrm{mg} / \mathrm{dL}$. Pediatric Diabetes 19 1173-1182. (https://doi.org/10.1111/pedi.12700)

Ode KL, Frohnert B, Laguna T, Phillips J, Holme B, Regelmann W, Thomas W \& Moran A 2010 Oral glucose tolerance testing in children with cystic fibrosis. Pediatric Diabetes 11 487-492. (https://doi. org/10.1111/j.1399-5448.2009.00632.x)

Olivier AK, Yi Y, Sun X, Sui H, Liang B, Hu S, Xie W, Fisher JT, Keiser NW, Lei D, et al. 2012 Abnormal endocrine pancreas function at birth in cystic fibrosis ferrets. Journal of Clinical Investigation 122 3755-3768. (https://doi.org/10.1172/JCI60610)

Perano SJ, Couper JJ, Horowitz M, Martin AJ, Kritas S, Sullivan T \& Rayner CK 2014 Pancreatic enzyme supplementation improves the incretin hormone response and attenuates postprandial glycemia in adolescents with cystic fibrosis: a randomized crossover trial. Journal of Clinical Endocrinology and Metabolism 99 2486-2493. (https://doi. org/10.1210/jc.2013-4417)

Rotti PG, Xie W, Poudel A, Yi Y, Sun X, Tyler SR, Uc A, Norris AW, Hara M, Engelhardt JF, et al. 2018 Pancreatic and islet remodeling in cystic fibrosis transmembrane conductance regulator (CFTR) knockout ferrets. American Journal of Pathology 188 876-890. (https:// doi.org/10.1016/j.ajpath.2017.12.015)

Segerstolpe Å, Palasantza A, Eliasson P, Andersson EM, Andreasson AC, Sun X, Picelli S, Sabirsh A, Clausen M, Bjursell MK, et al. 2016 Single-cell transcriptome profiling of human pancreatic islets in health and type 2 diabetes. Cell Metabolism 24 593-607. (https://doi. org/10.1016/j.cmet.2016.08.020)

Sequeiros IM, Hester K, Callaway M, Williams A, Garland Z, Powell T, Wong FS \& Jarad NA 2010 MRI appearance of the pancreas in patients with cystic fibrosis: a comparison of pancreas volume in diabetic and non-diabetic patients. British Journal of Radiology 83 921-926. (https:// doi.org/10.1259/bjr/24009651)

Sheikh S, Gudipaty L, De Leon DD, Hadjiliadis D, Kubrak C, Rosenfeld NK, Nyirjesy SC, Peleckis AJ, Malik S, Stefanovski D, et al. 2017 Reduced beta-cell secretory capacity in pancreatic-insufficient, but not pancreatic-sufficient, cystic fibrosis despite normal glucose tolerance. Diabetes 66 134-144. (https://doi.org/10.2337/db16-0394)

Soave D, Miller MR, Keenan K, Li W, Gong J, Ip W, Accurso F, Sun L, Rommens JM, Sontag M, et al. 2014 Evidence for a causal relationship between early exocrine pancreatic disease and cystic fibrosis-related diabetes: a Mendelian randomization study. Diabetes 63 2114-2119. (https://doi.org/10.2337/db13-1464)

Soejima K \& Landing BH 1986 Pancreatic islets in older patients with cystic fibrosis with and without diabetes mellitus: morphometric and immunocytologic studies. Pediatric Pathology 6 25-46. (https://doi. org/10.3109/15513818609025923)

Sun X, Olivier AK, Yi Y, Pope CE, Hayden HS, Liang B, Sui H, Zhou W, Hager KR, Zhang Y, et al. 2014 Gastrointestinal pathology in juvenile and adult CFTR-knockout ferrets. American Journal of Pathology 184 1309-1322. (https://doi.org/10.1016/j.ajpath.2014.01.035)

Sun X, Yi Y, Xie W, Liang B, Winter MC, He N, Liu X, Luo M, Yang Y, Ode KL, et al. 2017 CFTR influences beta cell function and insulin secretion through non-cell autonomous exocrine-derived factors. Endocrinology 158 3325-3338. (https://doi.org/10.1210/en.201700187)

Uc A, Olivier AK, Griffin MA, Meyerholz DK, Yao J, Abu-El-Haija M, Buchanan KM, Vanegas Calderon OG, Abu-El-Haija M, Pezzulo AA, et al. 2015 Glycaemic regulation and insulin secretion are abnormal https://joe.bioscientifica.com

https://doi.org/10.1530/JOE-18-0468 (c) 2019 Society for Endocrinology Published by Bioscientifica Ltd. Printed in Great Britain 
in cystic fibrosis pigs despite sparing of islet cell mass. Clinical Science 128 131-142. (https://doi.org/10.1042/CS20140059)

Uhlen M, Fagerberg L, Hallstrom BM, Lindskog C, Oksvold P, Mardinoglu A, Sivertsson A, Kampf C, Sjostedt E, Asplund A, et al. 2015 Tissue-based map of the human proteome. Science 3471260419 (https://doi.org/10.1126/science.1260419)

van Meegen MA, Terheggen SWJ, Koymans KJ, Vijftigschild LAW, Dekkers JF, van der Ent CK \& Beekman JM 2013 CFTR-mutation specific applications of CFTR-directed monoclonal antibodies. Journal of Cystic Fibrosis 12 487-496. (https://doi.org/10.1016/j. jcf.2012.12.005)

Warnock GL, Meloche RM, Thompson D, Shapiro RJ, Fung M, Ao Z, Ho S, He Z, Dai LJ, Young L 2005 Improved human pancreatic islet isolation for a prospective cohort study of islet transplantation vs best medical therapy in type 1 diabetes mellitus. Archives of Surgery 140 735-744. (https://doi.org/10.1001/archsurg.140.8.735)
Westwell-Roper C, Dai DL, Soukhatcheva G, Potter KJ, van Rooijen N, Ehses JA \& Verchere CB 2011 IL-1 blockade attenuates islet amyloid polypeptide-induced proinflammatory cytokine release and pancreatic islet graft dysfunction. Journal of Immunology 187 2755-2765. (https://doi.org/10.4049/jimmunol.1002854)

Wilschanski M \& Novak I 2013 The cystic fibrosis of exocrine pancreas. Cold Spring Harbor Perspectives in Medicine 3 a009746.

Yi Y, Norris AW, Wang K, Sun X, Uc A, Moran A, Engelhardt JF \& Ode KL 2016 a Abnormal glucose tolerance in infants and young children with cystic fibrosis. American Journal of Respiratory and Critical Care Medicine 194 974-980. (https://doi.org/10.1164/rccm.201512-2518OC)

Yi Y, Sun X, Gibson-Corley K, Xie W, Liang B, He N, Tyler SR, Uc A, Philipson LH, Wang K, et al. 2016b A transient metabolic recovery from early life glucose intolerance in cystic fibrosis ferrets occurs during pancreatic remodeling. Endocrinology 157 1852-1865. (https:// doi.org/10.1210/en.2015-1935)

Received in final form 19 December 2018

Accepted 13 February 2019

Accepted Preprint published online 13 February 2019 (c) 2019 Society for Endocrinology Published by Bioscientifica Ltd. 